\title{
2015, ano ventureiro para os estudos madrigalegos
}

\author{
Lidia LóPEz TEIXEIRo \\ Universidad Complutense de Madrid \\ Dpto. de Filología Románica, Filología Eslava y Lingüística General \\ lilope03@ucm.es
}

O curso 2014-2015 veu acompañado de moitas novidades e propostas interesantes para o Centro de Estudos Galegos, dentro e fóra do ámbito universitario. Marcado xa para sempre por feitos como a homenaxe á escritora Begoña Caamaño (recentemente falecida) ou a estrea do filme multipremiado A Esmorga, foi tamén un período moi fértil para os eventos literarios, e moi especialmente os poéticos. De entre o grande abano de posibilidades que Madrid ofreceu, no entanto, destacou polo éxito e seguimento, a celebración dun encontro científico: as Xornadas Internacionais UCMUNED 2014. Literatura galega: identidade, alteridade e exilio. Froito serodio do lectorado de Ricardo Pichel, que remataba neste período, a publicación que delas se derivou, o Número Especial 18 de Madrygal, amosa perfectamente o espíríto e alta calidade que se mantivo neste encontro, xunto cos esforzos realizados polo equipo e dirección que fixo posíbeis ambas as dúas cousas ${ }^{1}$. Con posterioridade a isto, produciríase a incorporación da nova lectora Lidia López ao CEG e Ricardo, polo seu apoio incondicional, axuda, e inestimábel consello e asesoramento, foi designado colaborador honorífico do Centro de Estudos.

Ao pouco de dar comezo o período lectivo, as actividades e oferta cultural comezou a multiplicarse: concertos, actividade literaria... Desde a universidade tentouse en todo momento tanto difundilos como apoiar as iniciativas galegas na capital, a través da colaboración ou asistencia. Unha moi relevante tivo lugar o día 23 de outono, coa presentación da Editorial Mar Maior en Madrid. Pensada para dar a coñecer ao mundo a literatura galega a través de traducións ao castelán, trátase dunha filial da consolidada Editorial Galaxia. $\mathrm{O}$ acto contou, entre outros, coa presenza do escritor e Director xeral da editorial, Víctor F. Freixanes. A profesora Carme Mejía, xunto co alumnado de románicas, tivo ocasión de asistir ao acto. Para os e as estudantes foi o primeiro contacto co galego e a súa cultura, mesmo antes de comezar as materias que lles eran propias desta lingua. O centro foi agasallado con algunhas obras durante a súa promoción e na actualidade recibe xenerosa e puntualmente as novidades orixinais en galego, das cales se nutre a nosa revista e biblioteca de lingua galega.

Aos dous meses, decembro xestou varias actividades onde o CEG participou en maior ou menor medida, coa intención sempre de garatir tanto a difusión da cultura galega como de proporcionar tamén contextos onde a comunidade universitaria poida coñecer de primeira man a nosa literatura, lingua ou algúns dos escritores máis famosos, como é o caso de Claudio Rodríguez Fer. Con motivo da presentación do libro Valente Vital (Ginebra, Saboya, Paris), o alumnado de lingua galega tivo ocasión de coñecer ao responsábel da Cátedra de Estudos José Ángel Valente e de entrevistalo. Aínda

\footnotetext{
${ }^{1}$ Pódese consultar este número especial, á integra, no sitio web da revista: https://revistas.ucm.es/ index.php/MADR/issue/current.
} 
que a entrevista permanece inédita, froito deste encontro si foi posíbel a súa colaboración poética coa revista Madrygal. Este non foi o primeiro contacto coa poesía en galego na UCM. Uns días antes, o catro de decembro, xa o alumnado asistira ás "III Jornadas Plurilingües de la Península Ibérica". Aínda que non se trataba, esta vez, de poesía galega, a descoñecida e fermosísima poesía en lingua checa floreceu traducida a moitas linguas, entre elas o galego. Así mesmo, outros dous recitais de relevancia aos que tivemos o pracer de asistir como convidados foron o da presentación do libro colectivo Esferografías, do Grupo Bilbao (ed. Lastura), e mais o orixinalísimo novo libro de Rafa Yáñez, Farewell (ed. Adeshoras), presentado nin máis nin menos que no auditorio da Fundación Ortega y Gasset.

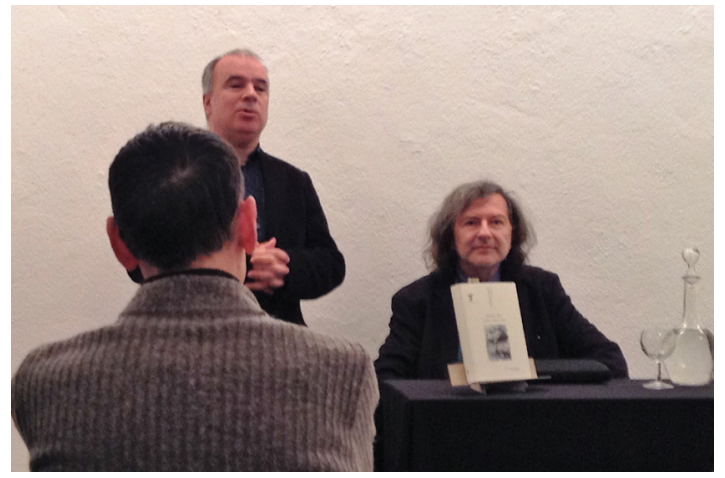

Claudio Rodríguez Fer na presentación do libro Valente Vital

Como remate do ano, a lectora de galego foi convidada a compartir as súas experiencias lingüísticas xunto con dúas docentes de Ensino Medio do País Vasco, Lourdes Moja Intxaurraga e Begoña Medina Sánchez, nun encontro organizado pola profesora Carmen Mejía para a materia do Mestrado de Estudos Literarios, Literaturas e Identidade Nacional na Península Ibérica. Nesta aula aberta, tratáronse as situacións lingüísticas e os sistemas educativos da Galiza e Euskadi, a través de testemuños en primeira persoa e do diálogo e interacción co público, que se mostrou moi interesado no tema.

En 2015, retomouse o labor cultural despois do Nadal e as festividades de Aninovo e reis, case en marzo. Como non podía ser doutro xeito, en Madrid, a cidade na que casou e vivíu a nosa

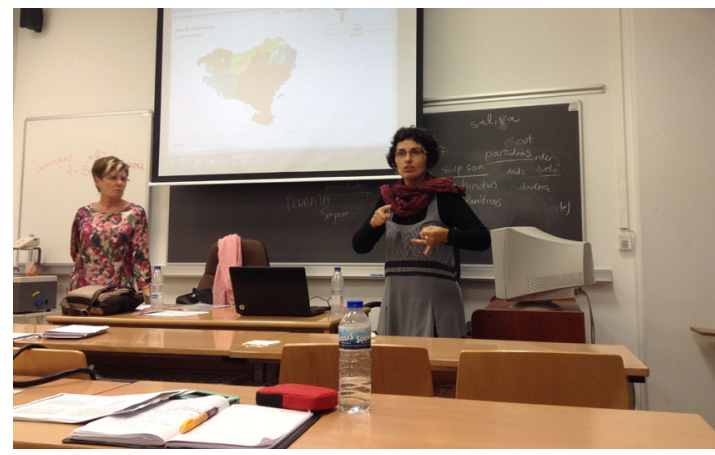

Lourdes Moja e Begoña Medina falan do caso do euskera na materia de literaturas peninsulares

escritora por excelencia, non faltou o Recital rosaliano o día da súa conmeración, de 24 de febreiro. Diante da súa casa na rúa Ballesta, o poeta Manuel Pereira leu o manifesto da Asociación de Escritoras e Escritores en Lingua Galega e as persoas asistentes leron algúns dos poemas máis emblemáticos da autora de Follas Novas. Desde a súa casa fíxose un breve roteiro ata a Igrexa de San Ildefonso, onde casaron Rosalía e mais Manuel Murguía.

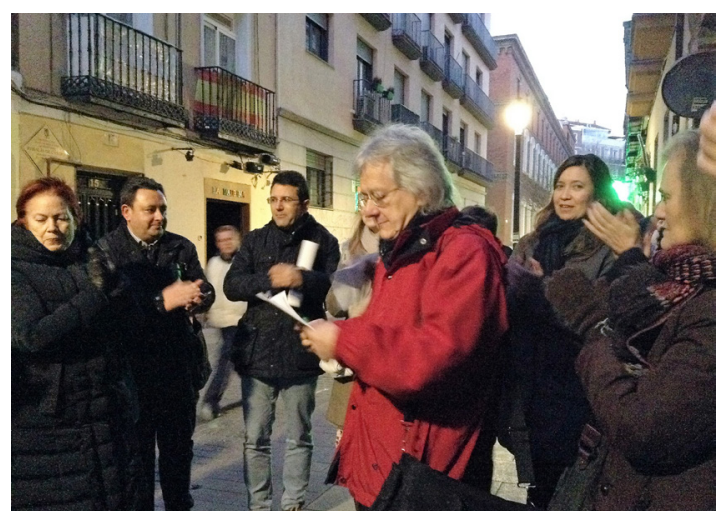

Manuel Pereira le o manifesto Rosaliano

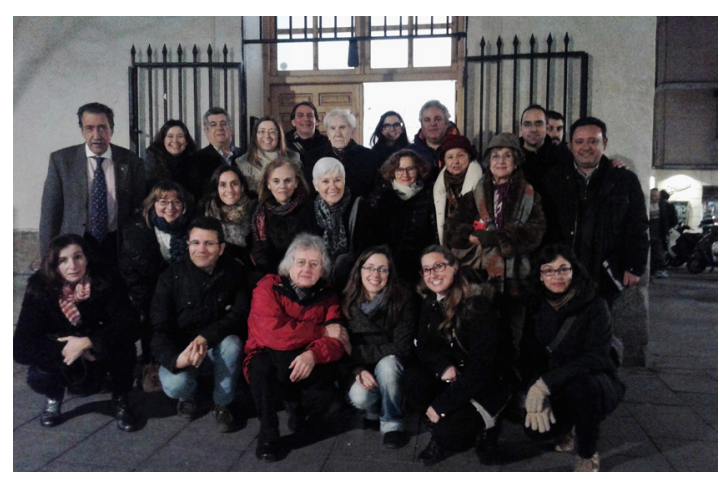

Madrigalegas na Igrexa de San Ildefonso 
Precendo á xa tradicional "Semana de las Letras", ademais de asistir á Tertulia de Arco poético do 12 de marzo, onde o poeta Manuel Pereira era o convidado, tivemos ocasión de colaborar cunha nova iniciativa da facultade de Filoloxía na UCM, a celebración do Día da poesía. Ao longo de toda a xornada, diferentes actividades poéticas programadas simultaneamente fóronse desenvolvendo nos diferentes emprazamentos da facultade. O alumnado de lingua galega participou primeiramente na sesión de micro aberto, onde recitaron unha escolma de poemas de autores e autoras como Celso Emilio Ferreiro, Olga Novo, María Lado... Logo, tivo lugar unha mesa redonda sobre o Grupo Bilbao e o cambio xeracional no seu seo. Despois de estabelecerse un animado debate sobre a xénese e requisitos das e dos integrantes, as persoas da mesa concluíron o acto tamén cun breve recital.
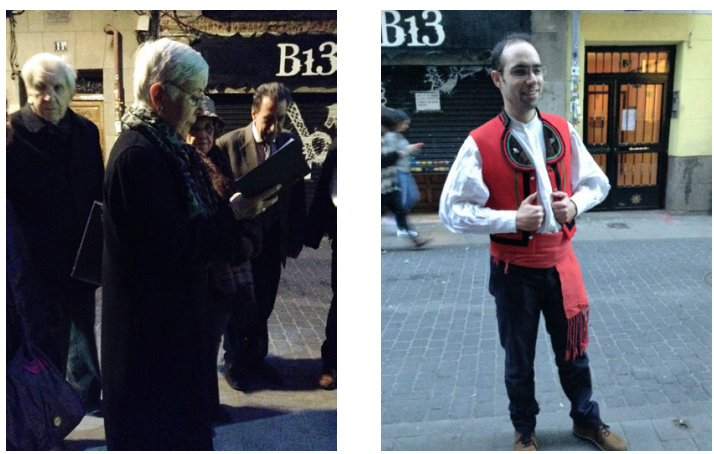

Inés Canosa no roteiro rosaliano e Rafa Yáñez recitando "Un repoludo gaiteiro", de Cantares gallegos

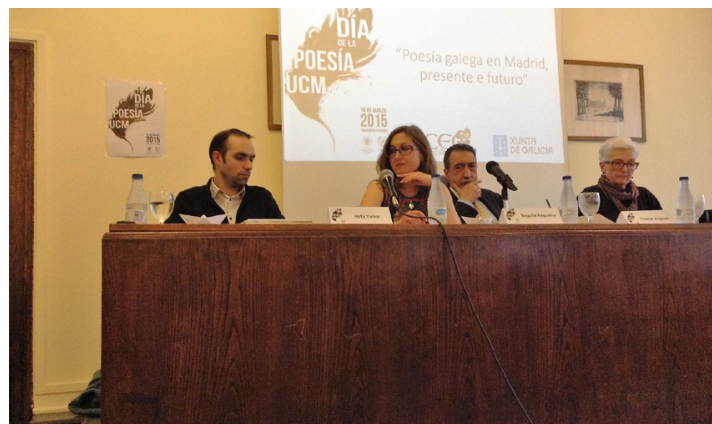

Rafa Yáñez, Begoña Regueiro, Vicente Araguas e Luz Pichel na mesa redonda do Día da poesía UCM

O mes de abril trouxo consigo o XI Congreso da Asociación Internacional de Estudos Galegos (AIEG), así como as propostas culturais e literarias da "Semana de las Letras".

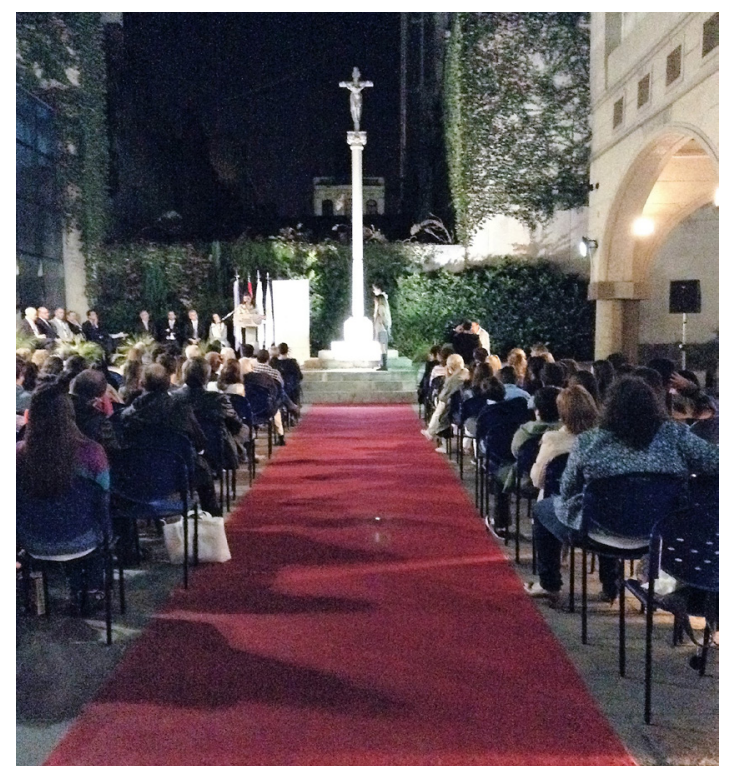

Recepción no colexio arxentino-galego Santiago Apóstol, en Buenos Aires

O congreso, celebrado en Buenos Aires entre o 6 e o 8 de abril supuxo a renovación da directiva da asociación da AIEG por un novo período de tres anos, así como a discusións de propostas dun novo lugar para a celebración do seguinte encontro en 2018. A candidatura de Madrid, como futura sede para o XII Congreso Internacional, elaborada por integrantes do Centro de Estudos Galegos da UCM, foi votada e aprobada, xunto cunha nova dirección da Asociación con Carme Mejía como Presidenta, Ricardo Pichel como Secretario, Lidia López como Secretaria de Relacións Institucionais e Ana Acuña na Tesouraría. Os postos de vogais foron ocupados por Javier Rivero, John Thompson, María Boguszewicz e Diego Muñoz.

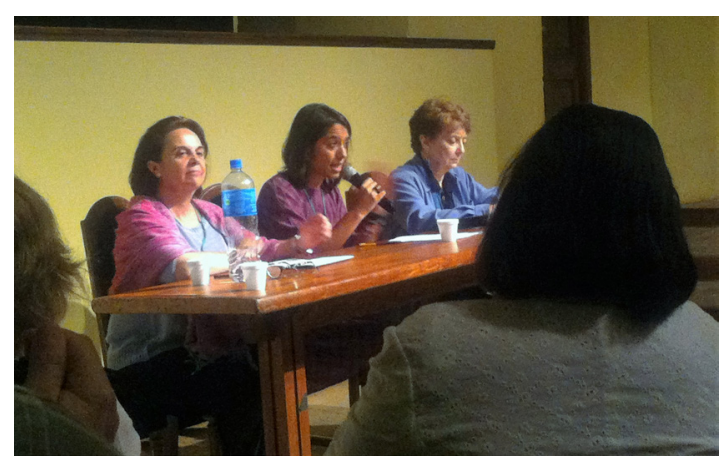

Carmen Mejía, Olga Castro e Kathleen March na clausura do XI Congreso da AIEG 

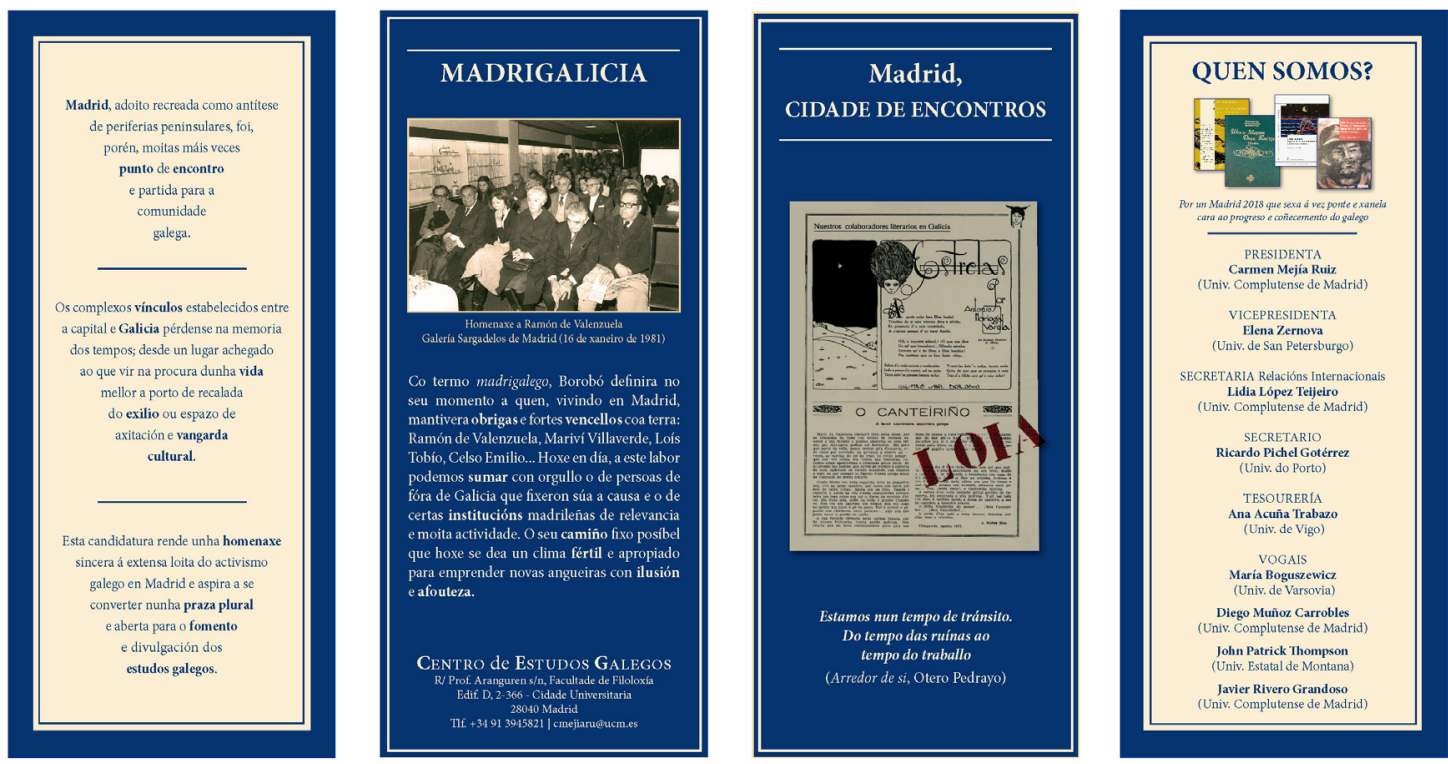

Tríptico da candidatura á nova Directiva da AIEG 2015-2018

A "V Semana Complutense de las Letras", pola súa banda, deu soporte e serviu de fío condutor para tres iniciativas culturais financiadas e organizadas polo CEG. Xa asentada dentro da comunidade universitaria despois dun lustro, caracterízase polas súas actividades culturais abertas e innovadoras. Trátase dun trampolín perfecto para dar a coñecer a nosa lingua e culturas e facer visible á participación da comunidade universitaria a nosa programación traballo.

Das catro actividades presentadas, quizais a máis emotiva foi a primeira delas, a homenaxe a Begoña Caamaño dirixida por Chus Nogueira e Camiño Noia. Despois das súas respectivas intervencións e o visionado dunha videomontaxe realizada polo profesor Manuel Forcadela, o estudantado de lingua galega leu textos de viaxes da autora ilustrados con fotografías que eles mesmos seleccionaron. $\mathrm{O}$ día seguinte, 21 de abril, tivo lugar o obradoiro de música e literatura popular de transmisión oral, a cargo de Noemi Basanta Llanes. A investigadora e música, ademais de deleitar co seu virtuosismo musical, fixo un percurso pola transmisión e historia da música tradicional ao tempo que presentou os instrumentos tradicionais e a súa orixe dun xeito moi didáctico e ameno.

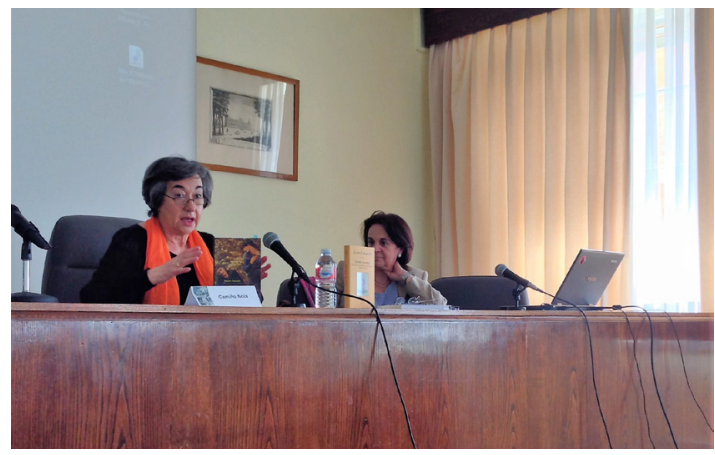

Camiño Noia na homenaxe a Begoña Caamaño

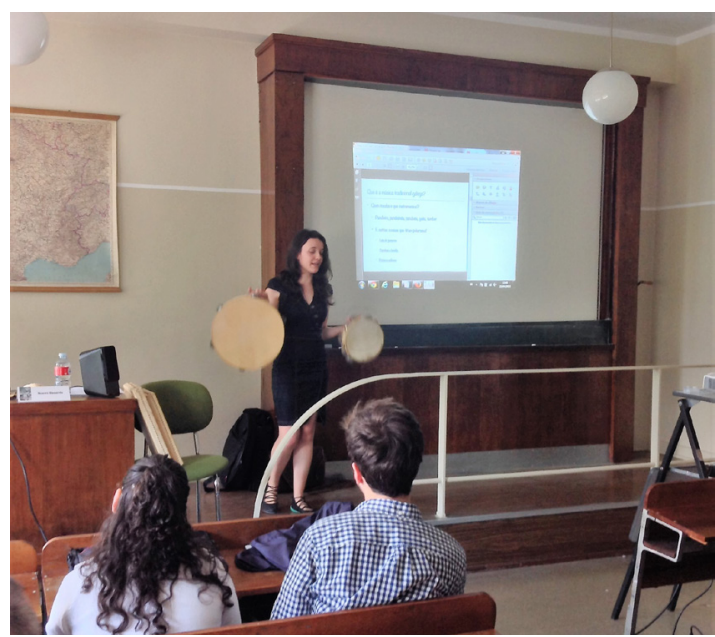

Noemi Basanta Llanes no obradoiro de música e literatura popular 
A homenaxe ao persoeiro das Letras Galegas de 2015, Xosé Fernando Filgueira Valverde, fíxose coincidir coa presentación do volume 17 da revista Madrygal. O acto, celebrado o día 22 de abril na Biblioteca Histórica Marqués de Valdecillas da UCM, constou dunha primeira parte referida á obra de Filgueira Valverde, unha pequena descrición biográfica e revisión da súa obra, seguida dunha intervención da súa filla, a fotógrafa Ángeles Filgueira e da lectura dunha carta escrita polo seu neto, Jorge Urrea. Ángeles, que non adoita aceptar peticións deste tipo, si accedeu a colaborar coa UCM e a súa presenza trouxo bastante afluencia de público. Logo das exposicións sobre o Día das Letras Galegas, Vicente Araguas introduciu a presentación do volume 17 de Madrygal, xunto con Xavier Frías e Javier Rivero. A continuación, procedeuse á lectura dos textos de creación e tradución presentes nese número polos seus autores e pechou o acto Noemi Basanta, quen tivo a amabilidade de cantar unhas coplas do propio Filgueira.

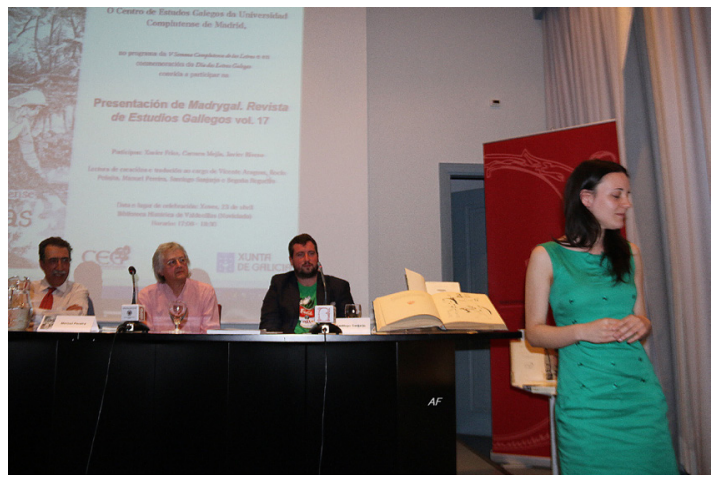

Vicente Araguas, Manuel Pereira, Santiago Sanjurjo e Noemi Basanta na presentación de Madrygal

Apenas finalizada a "Semana das Letras", o CEG foi convidado á outra celebración do día das Letras Galegas, organizada no Ateneo de Madrid. Por diante, aínda quedaría case dous meses de traballo intenso, cos preparativos da visita de estudos de fin de curso a Galicia. Realizouse, despois de adiala por mor do período de exames, entre o 25 e o 29 de xuño. Durante cinco días o estudantado puido coñecer de primeira man a lingua, cultura e patrimonio galegos viaxando por boa parte do noso país. Grazas á axuda desinteresada e entusiasta dos profesores José Luís López Taboada e Ernesto

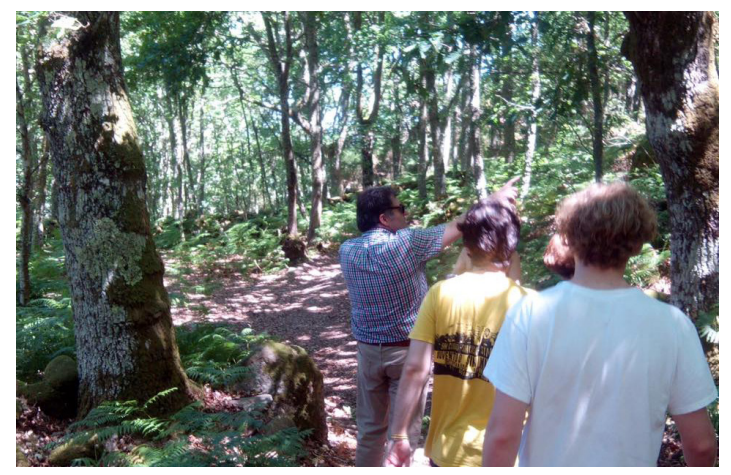

José Luís López Taboada explicando a vexetación autóctona no descenso ao castro de Armeá

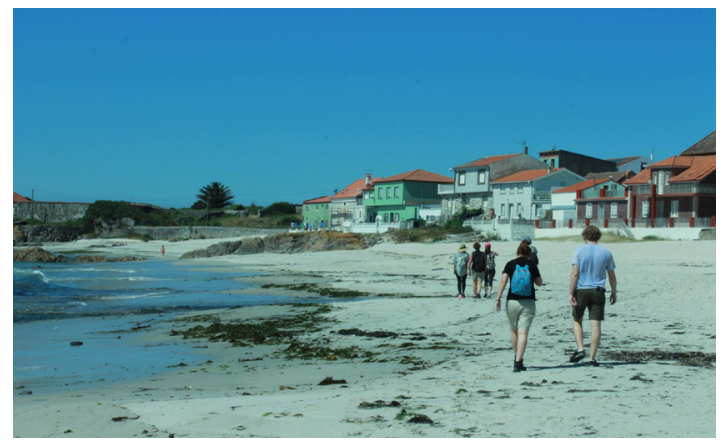

Regreso a Corrubedo durante a ruta de sendeirismo

Xosé González Seoane, ás filológas Tamara Dosantos e Noa Presas (e tantos outros nomes que colaboraron para o bo desenvolvemento do noso roteiro), puidemos visitar máis dunha ducia de paraxes e monumentos singulares e déronnos, coa súa calidez humana, unha acollida inmellorábel. Fomos coñecendo os castros de Santo Tomé e Armeá en Ourense, paseamos pola ruta termal en Outariz, visitamos o Pórtico do Paraíso da catedral de Ourense, accedemos en exclusiva ao Santuario de Santa Mariña de Augas Santas, entramos na colexiata de Xunqueira de Ambía, desprázamonos ata o mosteiro de San Pedro de Rochas... E aínda nos achegamos ata o parque natural de Corrubedo ao longo dunha ruta de sendeirismo de 16 quilómetros, visitar Padrón, disfrutar da zona vella de Santiago, das festas do afamado barrio de San Pedro, do casco medieval de Noia nunha visita nocturna... Non faltou a visita á facultade de Historia, co seu magnífico claustro e biblioteca, e ao Instituto da Lingua Galega, para dar a coñecer o labor de investigación e os seus proxectos en curso, e tomar conciencia da importancia do seu traballo. 


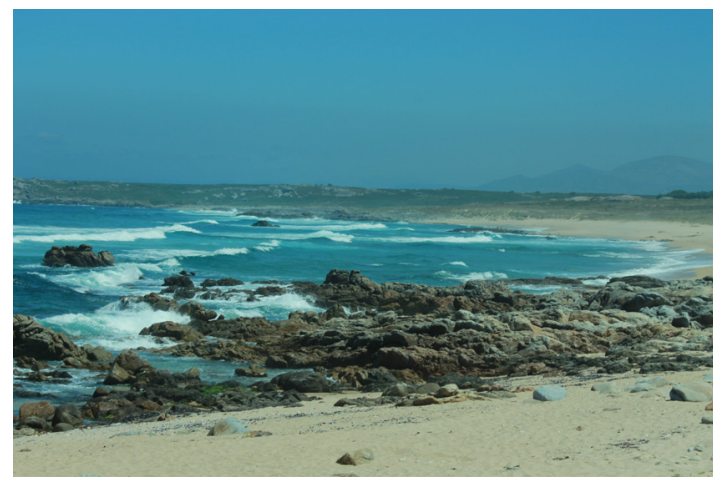

Praia de Balieiros (Corrubedo)

Despedimos o ano, xa de volta en Madrid, cunha nova triste, o peche do café Comercial. Tamén coñecido como café Bilbao, por atoparse na céntrica glorieta homónima, na zona

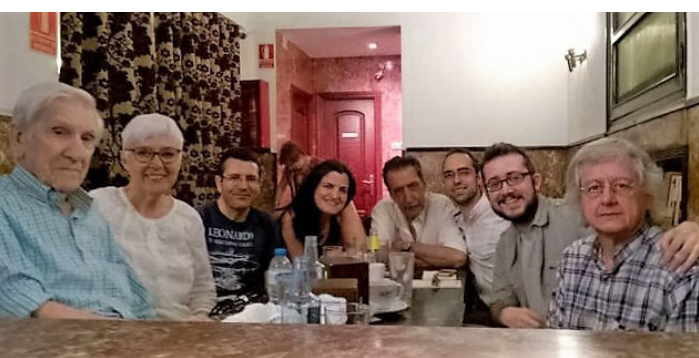

O último faladoiro do Grupo Bilbao no Café Comercial (28 de xuño de 2015)

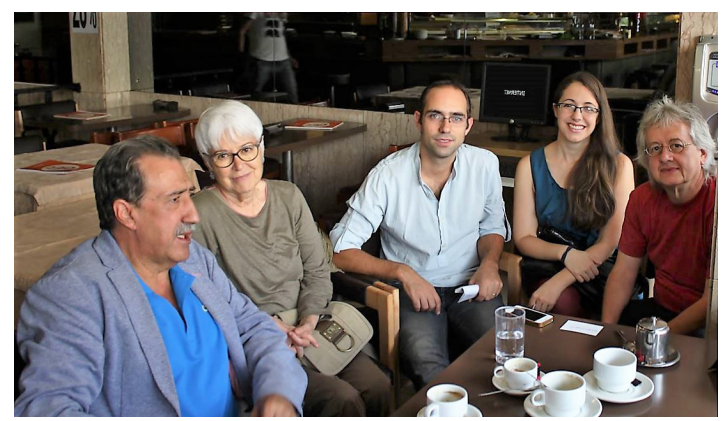

O primeiro faladoiro do Grupo Bilbao no Café Santander (3 de outono de 2015, foto: José Luis Fraiz)

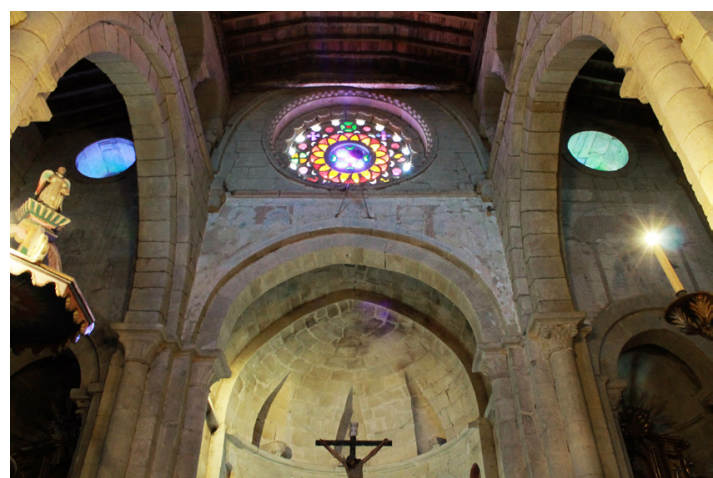

Santa Mariña de Augas Santas (Ourense)

de Malasaña, era un dos locais máis emblemáticos e coñecidos. Aberto desde finais do século XIX, este café deu nome ao Grupo Bilbao e viña sendo a sede, desde os noventa, da tertulia madrigalega do faladoiro, celebrada cada sábado último de mes. Cando a información se fixo pública, moitos medios se fixeron eco dela e o faladoiro precisaba, polo ben da súa continuidade, localizar un novo espazo, ameno, para seguir realizando os seus encontros mensuais. Este lugar, que ten visos de consolidarse como a nova parada madrigalega, pasou a ser o Café Santander. No lateral da Praza de Santa Bárbara e sen saír da mesma zona, a tertulia xa comezou a volta do verán tras as grandes cristaleiras da cafetaría e volve estar tan concorrida coma sempre.

Agardamos que o vindeiro ano sexa igual de fructífero ou máis, coma este que xa vai rematando. Que veña cangado de boas e novas achegas madrigalegas e, sobre todo, que siga servindo non só para falar en galego e de Galicia, se non para continuar tendendo pontes e estreitando lazos dentro do tecido cultural galego no exterior, sempre dispostos e abertos a novas colaboracións e traballos. 